\title{
BMJ Open A protocol for a scoping and qualitative study to identify and evaluate indications for damage control surgery and damage control interventions in civilian trauma patients
}

\author{
Derek J Roberts, ${ }^{1,2,3,4}$ David A Zygun, ${ }^{5}$ Andrew W Kirkpatrick, ${ }^{1,3}$ Chad G Ball, ${ }^{1,3,6}$ \\ Peter D Faris, ${ }^{7}$ Niklas Bobrovitz, ${ }^{8}$ Helen Lee Robertson, ${ }^{9}$ H Thomas Stelfox ${ }^{2,4,10}$
}

To cite: Roberts DJ, Zygun DA, Kirkpatrick AW, et al. A protocol for a scoping and qualitative study to identify and evaluate indications for damage control surgery and damage control interventions in civilian trauma patients. BMJ Open 2014;4:e005634. doi:10.1136/bmjopen-2014005634

- Prepublication history and additional material is available. To view please visit the journal (http://dx.doi.org/ 10.1136/bmjopen-2014005634).

Received 6 May 2014 Accepted 12 June 2014

CrossMark

For numbered affiliations see end of article.

Correspondence to Dr Derek J Roberts; Derek.Roberts01@gmail.com

\section{ABSTRACT}

Introduction: Initial abbreviated surgery with planned reoperation (damage control surgery) is frequently used for major trauma patients to rapidly control haemorrhage while limiting surgical stress. Although damage control surgery may decrease mortality risk among the severely injured, it may also be associated with several complications when inappropriately applied. We seek to scope the literature on trauma damage control surgery, identify its proposed indications, map and clarify their definitions, and examine the content and evidence on which they are based. We also seek to generate a comprehensive list of unique indications to inform an appropriateness rating process.

Methods and analysis: We will search 11 electronic bibliographic databases, included article bibliographies and grey literature sources for citations involving civilian trauma patients that proposed one or more indications for damage control surgery or a damage control intervention. Indications will be classified into a predefined conceptual framework and categorised and described using qualitative content analysis. Constant comparative methodology will be used to create, modify and test codes describing principal findings or injuries (eg, bilobar liver injury) and associated decision variables (eg, coagulopathy) that comprise the reported indications. After a unique list of codes have been developed, we will use the organisational system recommended by the RAND/University of California, Los Angeles (RAND-UCLA) Appropriateness Rating Method to group principal findings or injuries into chapters (subdivided by associated decision variables) according to broader clinical findings encountered during surgical practice (eg, major liver injury).

Ethics and dissemination: This study will constitute the first step in a multistep research programme aimed at developing appropriate, evidence-informed indications for damage control in civilian trauma patients. With use of an integrated knowledge translation intervention that includes collaboration with surgical practice leaders, this research may allow for development of indications that are more likely to be relevant to and used by surgeons. Ethics approval is not required for this study.
Strengths and limitations of this study

Highly sensitive search strategy covering 11 electronic bibliographic databases, numerous conference proceedings, included article bibliographies, expert files and the grey literature.

- Article selection, data extraction and qualitative coding of the indications for damage control surgery and damage control interventions will be performed independently by two investigators to increase reliability of the study results.

- Although the study will identify candidate indications for systematic review for evidence of validity and reliability, the quality of the included studies will not be assessed in this study given its scoping design.

\section{BACKGROUND}

Injury remains a leading international health problem. ${ }^{1}{ }^{2}$ Worldwide each year, injury occurs among 700 million people, including 30 million North Americans, and results in 5 million deaths. ${ }^{3}{ }^{4}$ In 2010, road traffic (bicycle, motorcycle, motor vehicle and pedestrian) injury was the fifth leading cause of years of life lost due to premature mortality in the USA. ${ }^{1}$ Injury is also the leading cause of quality years of life lost and preventable morbidity in North America. ${ }^{3} 4$

As injured patients may lose blood at rates greater than 20 units/h, haemorrhage accounts for at least half of traumatic deaths within $24 \mathrm{~h}$ of hospitalisation, many of which are potentially preventable. $^{5-7}$ Exsanguination, or blood loss exceeding $40 \%$ of total blood volume with ongoing bleeding, and contamination secondary to intra-abdominal hollow viscus and/or pancreaticobiliary injuries, are frequently associated with development of a 'lethal triad' of hypothermia, acidaemia and coagulopathy (defined clinically as the absence of visible 
blood clots during surgery or biochemically as an elevated international normalised ratio, prothrombin time or partial thromboplastin time). ${ }^{5-11}$ This triad has been linked with a high risk of mortality despite conventional surgical attempts at controlling haemorrhage and contamination. ${ }^{11} 12$

\section{Innovation and current utilisation of trauma damage control surgery}

The steps of a standard trauma laparotomy (also known as single-stage trauma laparotomy) include rapid evacuation of intra-abdominal blood followed by fourquadrant packing with laparotomy pads, complete abdominal exploration and definitive repair of all injuries. ${ }^{13}$ Although this approach is effective for most patients with abdominal injuries, prolonged or extensive

Table 1 Commonly described stages of civilian damage control surgery

\begin{tabular}{ll}
\hline Stage & Description \\
\hline DC0* & $\begin{array}{l}\text { Initiation of damage control resuscitation and } \\
\text { selection of patients appropriate for a damage } \\
\text { control versus single-stage surgical procedure } \\
\text { (the focus of this proposal) }\end{array}$ \\
Abbreviated surgical operation: Interventions \\
utilised may include perihepatic packing of liver \\
and juxtahepatic venous injuries, wide drainage \\
(with closed suction drains) and gauze packing of \\
pancreatic head injuries (as opposed to attempts \\
at pancreaticoduodenectomy or Whipple's \\
procedure), resection of major gastrointestinal tract \\
injuries without reanastomosis, pulmonary \\
tractotomy, non-anatomic resection of peripheral \\
lung injuries, use of temporary intravascular \\
shunts to bridge injured vascular structures, and \\
insertion of balloon occlusion catheters into \\
bleeding wound tracts. This stage typically ends \\
with temporary abdominal, thoracic, or other \\
closure using one of many different techniques \\
Resuscitation in the ICU: This frequently includes \\
vigorous rewarming of hypothermic patients, fluid \\
and blood resuscitation, correction of \\
coagulopathy and acidaemia and support of \\
injured lungs and failing or failed kidneys \\
Reoperation with attempted completion of \\
definitive surgical repairs and formal closure of the \\
abdomen, chest or other bodily region, where \\
possible: This stage often also includes a search \\
for missed intracavitary injuries as well as creation \\
of ostomies, and may include placement of \\
surgical feeding tubes \\
Reconstructive surgery: This includes definitive \\
fascia-to-fascia closure of the abdominal wall in a \\
patient initially managed with a planned ventral \\
hernia (ie, split-thickness skin graft placed directly \\
atop granulating viscera of the patient's open \\
abdomen)
\end{tabular}

operation in select severely injured patients leads to decreases in body temperature and arterial $\mathrm{pH}^{12-14}$ Administration of large amounts of resuscitation fluid during single-stage laparotomy also frequently exacerbates or promotes onset of coagulopathy. ${ }^{11} 1315$ As such, some major trauma patients have been reported to develop the lethal triad and succumb to their injuries when single-stage laparotomy was utilised. ${ }^{12} 1416$

In an attempt to control coagulopathic bleeding in patients with major abdominal injuries, Stone $e t a l^{17}$ proposed the abbreviated laparotomy with use of gauze packing and other temporising injury repair techniques, followed by planned relaparotomy for definitive injury repair (usually within 24-72 h). This approach was later named 'damage control' in 1993 and represents a paradigmatic change in surgical thinking that focuses more on the physiology of the patient than the need to repair all injuries during the index operation. ${ }^{13}{ }^{18}$ Damage control evolved from the use of compressive perihepatic packing for patients with major liver injuries, ${ }^{11}{ }^{19-25}$ and is now frequently recommended to manage select severely injured patients with head and neck, thoracic, abdominal and extremity injuries. ${ }^{5}{ }^{26-30}$ Although the suggested number and characteristics of procedural stages vary, they have most frequently been reported to include 'damage control ground 0' (preoperative resuscitation and selection of patients appropriate for damage control); damage control 1 (initial abbreviated operation for control of haemorrhage and contamination); damage control 2 (intensive care unit (ICU) resuscitation); damage control 3 (reoperation for definitive repair, which may require multiple operations); and damage control 4 (reconstructive surgery; table 1). ${ }^{31-33}$

Despite being considered a breakthrough in injury care, there has been limited evaluation of damage control compared with single-stage surgery for management of trauma patients. ${ }^{34}$ A Cochrane systematic review on damage control laparotomy conducted in 2010 identified only seven relevant observational ${ }^{18} \quad 23 \quad 26 \quad 35-38$ studies and no randomised controlled trials (RCTs). ${ }^{34}$ Although this review suggested that 'good quality RCTs comparing damage control laparotomy with traditional, immediate repair of abdominal injuries [ie, single-stage laparotomy]' were warranted, ${ }^{34}$ no trial protocols have appeared in clinical trials registries or peer-reviewed journals. While exact reasons for this are unknown, it may be due to the loss of perceived clinical equipoise among the surgical community regarding the effectiveness of damage control surgery during the adoption phase of the procedure. ${ }^{39}$ Surgeons have therefore instead focused on defining the effectiveness of individual stages of the damage control process (damage control 0-4). ${ }^{33} 40-50$

Several studies have recently reported data suggesting that damage control surgery may be overutilised. ${ }^{51-53}$ This is concerning as the procedure has been associated with substantial complications among survivors. ${ }^{54} 55$ A recent retrospective cohort study reported that one in 
five patients who received damage control laparotomy at a high-volume trauma centre between 2004 and 2008 failed to meet at least one of the traditional indications. ${ }^{52}$ In this study, only $33 \%$ were acidotic, $43 \%$ hypothermic and $48 \%$ coagulopathic on arrival to the ICU from the operating room. ${ }^{52}$ Although it could be argued that these patients may have simply been selected for the procedure before they developed the lethal triad, another retrospective cohort study suggested that applying damage control to patients who are not in physiological extremis could potentially lead to harm. ${ }^{53}$ In this study, use of damage control versus single-stage surgery in less-acutely ill trauma patients was associated with an increased risk of bowel ischaemia/perforation, sepsis and multiorgan failure; a prolonged hospital stay and an elevated risk of death. ${ }^{53}$

\section{Study rationale}

As no single set of appropriateness indications for damage control surgery exists, a large number of heterogeneous, sometimes non-specific, and even contradicting indications for the procedure have been proposed.$^{56-59}$ In addition to the lethal triad (or its component parts), indications have been suggested based on specific patient injuries, characteristics of the surgeon or healthcare team (eg, limited surgeon experience with major trauma), and even various trauma care structural or environmental factors (eg, a non-level I trauma centre with little surgical or intensive perioperative monitoring capabilities). Those based on biochemical or laboratory measurements $(\mathrm{eg}, \mathrm{pH})$ or the temperature or fluid resuscitation requirements of the patient (eg, the number of units of packed red blood cells administered) have also been reported to have a large number of cut-offs or decision thresholds. Moreover, while indications have been proposed across all phases of trauma surgical decision-making (prehospital, emergency department and intraoperative), it is unclear when the decision to perform damage control over single-stage surgery should best be made, with some authors suggesting that this should occur preoperatively and others intraoperatively. It also remains unknown whether indications differ according to the type of damage control procedure (eg, thoracic vs abdominal), whether indications for damage control surgery are dynamic (ie, an intraoperative conversion to a single-stage procedure could be performed if haemorrhage is rapidly controlled and patient physiology improves during the procedure) ${ }^{60} 61$ and which indications for the procedure may be valid and/or reliable. ${ }^{56}$ The above lack of consensus regarding damage control indications has frequently resulted in the inclusion of heterogeneous populations of patients with unbalanced determinants of outcomes in damage control studies, resulting in difficulties in comparing outcome data across investigations. $^{56} \quad{ }^{62}$ It also likely contributes to the aforementioned damage control practice variation. ${ }^{51-53}$
Study objectives

The objectives of this mixed methods study are to systematically scope the literature on damage control surgery in civilian trauma patients, identify its proposed indications, map and clarify their definitions and examine the content and evidence on which they are based. We also seek to generate a comprehensive and well-defined list of unique indications to inform a subsequent appropriateness rating process. ${ }^{63}$ To improve understanding of the findings on which the decision to perform damage control is based, indications will be classified into a predefined conceptual framework and categorised and described using qualitative content analysis. Constant comparative methodology will be used to create, modify and test codes describing the principal findings or injuries (eg, bilobar liver injury) and associated decision variables (eg, coagulopathy) that comprise the reported indications for damage control. After a unique list of codes have been developed, we will use the organisational system recommended by the RAND/ University of California, Los Angeles (RAND-UCLA) Appropriateness Method $(\mathrm{RAM})^{63}$ to group those describing findings or injuries and associated decision variables into chapters according to broader clinical findings encountered during surgical practice (eg, major liver injury). This work will constitute the first step in a multistep research programme aimed at development of evidence-informed indications for the appropriate use of damage control in civilian trauma patients.

\section{METHODS AND ANALYSIS \\ Protocol design}

Methods for this study were developed following suggestions for designing and performing scoping studies, ${ }^{64-66}$ conducting qualitative content analyses of textual data ${ }^{67-70}$ and for creating a list of indications for a surgical procedure. $^{63}$

\section{Conceptual framework}

Our scoping study will utilise a conceptual framework for damage control surgery indications (table 2). According to this framework, the decision to perform the procedure may occur in either the preoperative (prehospital or emergency department) or intraoperative phase of trauma surgical decision-making. ${ }^{71}$ This decision may be influenced by characteristics of the patient, providers, patient response to care and/or healthcare environment. Patient-based indications may be further subclassified according to those that are physiology based (eg, arterial $\mathrm{pH}<\mathrm{X}$ ), injury based (eg, pulmonary hilum injury) or resuscitation based (eg, administration of $>\mathrm{X}$ units of packed red blood cells). Injury-based indications can be further subcategorised by affected anatomical region (eg, neck, thorax or abdomen). These influencing factors are not meant to be mutually exclusive, as indications for damage control (eg, penetrating injury to the femoral artery) may be 
Table 2 Framework for conceptualising indications for damage control surgery among civilian trauma patients

\begin{tabular}{|c|c|c|c|c|}
\hline \multirow[b]{2}{*}{$\begin{array}{l}\text { Phase of trauma surgical } \\
\text { decision-making }\end{array}$} & \multicolumn{4}{|c|}{ Influencing characteristics or factors } \\
\hline & Patient & Providers & $\begin{array}{l}\text { Patient response } \\
\text { to care }\end{array}$ & $\begin{array}{l}\text { Healthcare } \\
\text { environment }\end{array}$ \\
\hline \multicolumn{5}{|l|}{ Preoperative } \\
\hline Prehospital & $\begin{array}{l}\text { Penetrating thoracic } \\
\text { or abdominal injury } \\
\text { with haemodynamic } \\
\text { instability* }\end{array}$ & $\begin{array}{l}\text { Lack of resources to } \\
\text { complete procedure or care } \\
\text { for patient postoperatively }\end{array}$ & $\begin{array}{l}\text { Persistent class IV } \\
\text { haemorrhagic } \\
\text { shock despite } \\
\text { resuscitation }\end{array}$ & $\begin{array}{l}\text { Multiple or mass } \\
\text { casualty incident }\end{array}$ \\
\hline Emergency department & $\begin{array}{l}\text { Status post } \\
\text { emergency } \\
\text { department } \\
\text { thoracotomy }\end{array}$ & $\begin{array}{l}\text { Anticipated prolonged time } \\
\text { to angioembolisation in a } \\
\text { patient with a pelvic fracture } \\
\text { and haemorrhagic shock }{ }^{*}\end{array}$ & $\begin{array}{l}\text { Massive } \\
\text { transfusion protocol } \\
\text { activated }\end{array}$ & \\
\hline Intraoperative & $\begin{array}{l}\text { Laboratory } \\
\text { coagulopathy } \\
(\mathrm{PT}, \mathrm{PTT} \text { or } \mathrm{INR} \geq \mathrm{X})\end{array}$ & $\begin{array}{l}\text { Surgeon's perception that } \\
\text { the abdominal fascia could } \\
\text { not be approximated without } \\
\text { tension }\end{array}$ & $\begin{array}{l}\mathrm{pH} \text { improves after } \\
\text { surgical bleeding is } \\
\text { controlled }\end{array}$ & $\begin{array}{l}\text { Lack of resources } \\
\text { to complete the } \\
\text { required operative } \\
\text { procedure }\end{array}$ \\
\hline
\end{tabular}

dependent on other factors (eg, concomitant haemorrhagic shock).

\section{Identifying relevant citations}

With the assistance of an information scientist/medical librarian (HLR), we used the COre Standard Ideal (COSI) model ${ }^{72}$ to develop an 'ideal' (highly sensitive) search strategy to identify indications for damage control surgery and damage control interventions in civilian trauma patients. We will search the following electronic bibliographic databases from their earliest available dates without language, publication date or other restrictions: Ovid MEDLINE and EMBASE, PubMed, Web of Science, Scopus and the six databases contained within the Cochrane Library (see online supplementary table S1 for details of our planned electronic bibliographic database search strategies). Additional citations will be located by contacting several damage control experts and by searching reference lists of included citations. In an attempt to find studies about to be published, we will also review abstracts from selected conferences held between 2009 and 2013, including meetings of the American Association for the Surgery of Trauma (AAST), Australasian Trauma Society, American College of Surgeons, Canadian Association of General Surgeons (CAGS), Eastern Association for the Surgery of Trauma (EAST), International Association for Trauma Surgery and Intensive Care (IATSIC), Trauma Association of Canada (TAC) and the Western Trauma Association (WTA).

In order to further increase the sensitivity and coverage of the search, one investigator (DJR) will also search the grey literature for additional indications not reported in the peerreviewed literature. This will involve searching relevant organisational websites (AAST, American College of
Surgeons, American Trauma Society, Australasian Trauma Society, British Trauma Society, CAGS, Critical Care Society, EAST, International Trauma Anaesthesia, National Trauma Research Institute, the Society of Trauma Nurses, TAC, http://www.trauma.org, and the WTA), Google Scholar (the first 10 web pages) and two clinical trial registries (http://www.clinicaltrials.gov and http://www. controlled-trials.com) using various combinations of the following key terms: trauma, injury, damage control, damage control surgery, bailout surgery, abbreviated surgery, planned reoperation, indication and predictor. We will also manually search several trauma and surgery textbooks. Textbooks of interest will be identified by searching for relevant books listed in Access Medicine (http://accessmedicine.com), the University of Calgary Ebrary (which contains more than 30000 book titles, and is located at http://site.ebrary.com.ezproxy.lib. ucalgary.ca/lib/ucalgary/home.action), and within the surgery category of Books@Ovid (http://www.ovid.com).

\section{Citation selection}

Two investigators (DJR and NB) will independently screen all identified citations in duplicate and select those that mention damage control, related terms (eg, staged laparotomy, planned relaparotomy or open abdominal management) or damage control interventions (eg, solid organ or intracavitary packing, temporary intravascular shunting or balloon catheter tamponade) in their title or abstract. These two investigators will then independently review the full text of the articles for these abstracts and include all citations (original or unoriginal) that involve civilian trauma patients and explicitly report one or more indications for damage control surgery or a damage control intervention. We will define an indication as an objective or subjective reason (or hypothetical clinical scenario) that the authors provided in order to guide surgeons 
towards the use of damage control (or a specific damage control intervention) over single-stage surgery (or a definitive surgical procedure). ${ }^{57-59}$ As no standardised or consensus definition yet exists, damage control will be broadly defined as a multistep operative intervention, which includes an abbreviated initial surgical procedure (or set of procedures) that aims to control obvious mechanical bleeding or contamination as compared to definitively repairing all injuries. Potentially relevant non-English language original articles will be identified for review by interpreters to assess whether they satisfy inclusion criteria. We will exclude animal studies and data sources involving exclusively non-civilian or burn patients and non-trauma patients with general (eg, intra-abdominal sepsis) or cardiovascular surgical emergencies. We will also exclude articles focusing solely on damage control for orthopaedic or neurological injuries, including spinal trauma. Eligibility disagreements will be resolved by consensus. Interinvestigator agreement regarding inclusion of titles/ abstracts and full-text articles will be quantified using the $\kappa$ statistic $^{73}$ and the ordinal $\kappa$-statistic agreement categories suggested by Altman. ${ }^{74}$

\section{Charting the data}

Two investigators (DJR and NB) will independently extract data on included articles as well as their reported indications using an electronic data extraction spreadsheet. This spreadsheet will be pilot tested using a randomly selected sample of 50 relevant English-language articles identified for inclusion in the scoping study. During pilot testing, the spreadsheet will be serially revised until consistent data collection can be demonstrated ( $\kappa$ statistic $\geq 0.75) .{ }^{73}$

We will extract data regarding: (1) characteristics of included citations; (2) author's institution(s); (3) number (where applicable) and characteristics of the patient population that received (or would be considered for) damage control surgery or a damage control intervention; (4) definitions of damage control surgery; (5) definitions of damage control indications and whether they were meant to be applied in the preoperative (prehospital or emergency department) or intraoperative phase of trauma surgical decision-making; (6) interventions suggested by authors to constitute damage control (in order to link the identified indications with suggested damage control techniques) and (7) outcomes associated with use of damage control surgery or a damage control intervention (see online supplementary table S2 for details regarding planned data items for collection). To identify candidate indications for systematic review for their evidence of validity and/or reliability, the type of study design for original research articles (abstract or full text) will be classified using the scheme developed by Oleckno. ${ }^{75}$ As cohort studies and case series are frequently confused, we will use the tool recommended by Dekker $e t a l^{76}$ to distinguish between these study designs.
Collating, synthesising and summarising the scoping study results

Characteristics of included articles and indications for damage control surgery and damage control interventions will be summarised using counts and proportions. Indications will be broadly classified into non-mutually exclusive categories of the above conceptual framework. We will also group indications according to patient age (adult vs paediatric depending on whether the included patients were $\geq 16$-years old vs $<16$-years old, respectively), country and year of article publication in order to assess whether differences appear to exist across regions, practice types or time periods. Statistical analyses will be performed using Stata MP V 13.1 (Stata Corp., College Station, Texas, USA).

\section{Qualitative content analysis of indications for damage control surgery and damage control interventions}

Two investigators (DJR and NB) will conduct an in-depth analysis of the identified indications for damage control surgery and damage control interventions using qualitative content analysis. ${ }^{67-70}$ While the initial stages of descriptive coding will begin as data are extracted from included manuscripts (basic unit of analysis=the text describing each indication), we anticipate that the process of coding and refinement of codes based on similarities and differences between indications will continue to emerge into the analysis phase of the study. This constant comparison method of analysis will be used to guide basic, open coding of indications independently between investigators. As the simultaneous extraction and coding of damage control indications is undertaken, our initial set of independently created codes will be reviewed, compared and then discussed by both investigators in order to test, build up and break down categories and subcategories describing the content on which the indications for damage control are based. Analysis will continue as relational similarities emerge in the form of natural groupings. Although it is possible that the resulting categories and subcategories could be similar to those outlined by the conceptual framework, our analysis will be carried out without any preconceived assumptions, given that existing theory on damage control indications is limited. ${ }^{68}$ Once the coding and analysis phase is complete, the full code list will be reorganised into two groupings: principal findings or injuries (eg, bilobar liver injury) and associated decision variables (eg, coagulopathy). Finally, in order to identify common dichotomous decision thresholds for measured indications or associated variables with explicitly reported cut-offs (eg, intraoperative $\mathrm{pH}>\mathrm{X}$ ), we will calculate medians or means summarising these thresholds as appropriate. Ranges for these data will also be reported in order to display the variation in reported cut-offs across the literature.

Organising the coded list of indications into RAM chapters Using the organisational system recommended by the RAM, and for ease of subsequent use, we will organise 
codes into 'chapters' according to the broader clinical findings that may be encountered during surgical practice. ${ }^{63}$ Codes for principal findings or injuries within these chapters will be subdivided by those for associated decision variables, therefore allowing for later creation of a series of RAM tables (see table 3 for examples of principal clinical findings and associated decision variables that may be used to create an interlinked RAM table). ${ }^{63}$

\section{ETHICS AND DISSEMINATION}

This study will constitute the first step in a multistep research programme aimed at developing appropriate, evidence-informed indications for damage control surgery and damage control interventions in civilian trauma patients. As all data will be collected from publicly available materials, this study does not require ethics approval. To facilitate knowledge translation efforts, our team will utilise an integrated approach to dissemination and translation of study findings that enhances interactivity and clinician engagement. ${ }^{77}$ This will be carried out to ensure that knowledge user participation is meaningful, productive and mutually beneficial across all phases of the research process. ${ }^{77}$

Several end-of-synthesis outputs are anticipated from this study that will subsequently be tailored for dissemination. Outputs will include a summative list of unique indications, an evidence map with validity/reliability assessments, a detailed evaluation of the content underlying indications and a RAM-based sorting of indications into chapters subdivided by associated decision variables.

Table 3 Example indication subdivided into its principal clinical finding and associated decision variables

\begin{tabular}{|c|c|}
\hline $\begin{array}{l}\text { Example principal } \\
\text { intraoperative clinical } \\
\text { finding }\end{array}$ & Major liver injury \\
\hline \multicolumn{2}{|c|}{ Example associated decision variables } \\
\hline Associated injuries & $\begin{array}{l}\text { Inaccessible major venous } \\
\text { injury }\end{array}$ \\
\hline Patient physiology at the & $\mathrm{pH} \leq \mathrm{X}$ \\
\hline beginning of laparotomy & $\mathrm{pH}>\mathrm{X}$ \\
\hline Patient physiology during & $\mathrm{pH}$ improves to $>\mathrm{X}$ \\
\hline laparotomy & $\mathrm{pH}$ does not improve to $>\mathrm{X}$ \\
\hline Extent of fluid resuscitation & $\begin{array}{l}\text { Transfusion of }>X \text { units of } \\
\text { packed red blood cells since } \\
\text { presentation }\end{array}$ \\
\hline \multirow{7}{*}{$\begin{array}{l}\text { Length of the operative } \\
\text { procedure } \\
\text { Hospital level of care } \\
\text { designation/ability to } \\
\text { provide comprehensive } \\
\text { perioperative care }\end{array}$} & $\leq \mathrm{X} \min$ \\
\hline & $>\mathrm{X} \min$ \\
\hline & American College of \\
\hline & Surgeons Committee on \\
\hline & $\begin{array}{l}\text { Trauma (ACS COT) level I } \\
\text { trauma centre }\end{array}$ \\
\hline & $\begin{array}{l}\text { ACS COT level II or III } \\
\text { trauma centre }\end{array}$ \\
\hline & $\begin{array}{l}\text { ACS COT level IV trauma } \\
\text { centre }\end{array}$ \\
\hline
\end{tabular}

To advance both awareness and trauma surgeon dialogue around damage control surgery indications and our research, we plan to disseminate the above outputs in user-friendly formats to knowledge users and their professional associations (TAC, AAST and the Australasian Trauma Society) at the national and international levels. When study results become available, presentations will be given tailored for academic and clinical audiences.

As the opinions of surgical practice leaders may be more likely to change surgical practice than clinical practice audit or guidelines, ${ }^{78}$ trauma surgeon involvement is likely to be essential for building a successful research programme on damage control surgery indications. A structured effort to purposively build relationships with and among several surgical practice knowledge users and practice leaders will therefore be undertaken. Engaging these individuals will help to ensure that study findings are driven by the primary change agents in the field. By involving knowledge users in the research team (DJR, AWK and CGB) and deliberately connecting with surgical practice leaders through established collegial and professional networks, we will work to ensure the research plan and emerging results are aligned with the needs of practicing trauma surgeons.

This research will identify and evaluate the proposed indications for damage control surgery and damage control interventions in civilian trauma patients. Our findings will be required to inform the subsequent creation of consensus indications among stakeholders using the RAM, and may ultimately allow for development of appropriate, evidence-informed consensus indications. They may also identify areas of uncertainty regarding whether damage control or single-stage surgery should be applied, which could guide the design of future RCTs comparing the two approaches. Development of evidence-informed indications for damage control surgery will therefore help standardise surgical practice, guide future clinical trials and improve care for seriously injured patients.

\section{Author affiliations}

${ }^{1}$ Department of Surgery, University of Calgary and the Foothills Medical Centre, Calgary, Alberta, Canada

${ }^{2}$ Department of Community Health Sciences, University of Calgary, Calgary, Alberta, Canada

${ }^{3}$ The Regional Trauma Program, University of Calgary and the Foothills Medical Centre, Calgary, Alberta, Canada

${ }^{4}$ Department of Critical Care Medicine, University of Calgary and the Foothills Medical Centre, Calgary, Alberta, Canada

${ }^{5}$ Division of Critical Care Medicine, University of Alberta, Edmonton, Alberta, Canada

${ }^{6}$ Department of Oncology, University of Calgary and the Foothills Medical Centre, Calgary, Alberta, Canada

${ }^{7}$ Alberta Health Sciences Research-Research Analytics, University of Calgary and the Foothills Medical Centre, Calgary, Alberta, Canada

${ }^{8}$ Nuffield Department of Primary Care Health Sciences, University of Oxford, Oxford, UK

${ }^{9}$ Health Sciences Library, University of Calgary, Calgary, Alberta, Canada

${ }^{10}$ Department of Medicine, University of Calgary and the Foothills Medical Centre, Calgary, Alberta, Canada 
Acknowledgements We acknowledge Kelly Mrklas, MSc for her helpful comments on earlier drafts of the manuscript.

Contributors All authors contributed to the study idea and design, and DJR, DAZ, AWK, CGB, PDF and HTS obtained study funding. HLR and DJR developed the search strategy and will execute the search strategy together. The remaining study methods were developed by all authors. DJR drafted the protocol, which was revised for intellectual input by all remaining authors. All authors have read and approved the manuscript for submission for peer review.

Funding This work is supported by an Alberta Innovates-Health Solutions Clinician Fellowship Award, a Knowledge Translation (KT) Canada Strategic Training in Health Research Fellowship, a KT Canada Research Stipend, and funding from the Canadian Institutes of Health Research (all awarded to DJR)

Provenance and peer review Not commissioned; externally peer reviewed.

Data sharing statement Although the submitted manuscript is a protocol, we plan to share our data with any who request it once results of the study become available.

Open Access This is an Open Access article distributed in accordance with the Creative Commons Attribution Non Commercial (CC BY-NC 4.0) license, which permits others to distribute, remix, adapt, build upon this work noncommercially, and license their derivative works on different terms, provided the original work is properly cited and the use is non-commercial. See: http:// creativecommons.org/licenses/by-nc/4.0/

\section{REFERENCES}

1. US Burden of Disease Collaborators. The state of US health, 19902010: burden of diseases, injuries, and risk factors. JAMA 2013:310:591-608.

2. Gore FM, Bloem PJ, Patton GC, et al. Global burden of disease in young people aged 10-24 years: a systematic analysis. Lancet 2011;377:2093-102.

3. Murray CJ, Lopez AD. Mortality by cause for eight regions of the world: Global Burden of Disease Study. Lancet 1997;349:1269-76.

4. Stelfox HT, Bobranska-Artiuch B, Nathens A, et al. Quality indicators for evaluating trauma care: a scoping review. Arch Surg 2010;145:286-95.

5. Burch JM, Ortiz VB, Richardson RJ, et al. Abbreviated laparotomy and planned reoperation for critically injured patients. Ann Surg 1992:215:476-83; discussion 483-4.

6. Kauvar DS, Lefering R, Wade CE. Impact of hemorrhage on trauma outcome: an overview of epidemiology, clinical presentations, and therapeutic considerations. J Trauma 2006;60:S3-11.

7. Holcomb JB, del Junco DJ, Fox EE, et al. The prospective, observational, multicenter, major trauma transfusion (PROMMTT) study: comparative effectiveness of a time-varying treatment with competing risks. JAMA Surg 2013;148:127-36.

8. Elerding SC, Aragon GE, Moore EE. Fatal hepatic hemorrhage after trauma. Am J Surg 1979;138:883-8.

9. Kashuk JL, Moore EE, Millikan JS, et al. Major abdominal vascular trauma-a unified approach. J Trauma 1982;22:672-9.

10. Cushman JG, Feliciano DV, Renz BM, et al. Iliac vessel injury: operative physiology related to outcome. J Trauma 1997;42:1033-40.

11. Ball CG. Damage control resuscitation: history, theory and technique. Can J Surg 2014;57:55-60.

12. Rotondo MF, Zonies DH. The damage control sequence and underlying logic. Surg Clin North Am 1997;77:761-77.

13. Mattox KL, Moore EE, Feliciano DV, eds. Trauma. 7th edn. China: McGraw Hill Companies Inc, 2013.

14. Hirshberg A, Mattox KL. Planned reoperation for severe trauma. Ann Surg 1995;222:3-8.

15. Holcomb JB, Jenkins $D$, Rhee $P$, et al. Damage control resuscitation: directly addressing the early coagulopathy of trauma. J Trauma 2007;62:307-10

16. Feliciano DV, Burch JM, Spjut-Patrinely V, et al. Abdominal gunshot wounds. An urban trauma center's experience with 300 consecutive patients. Ann Surg 1988;208:362-70.

17. Stone $\mathrm{HH}$, Strom PR, Mullins RJ. Management of the major coagulopathy with onset during laparotomy. Ann Surg 1983;197:532-5
18. Rotondo MF, Schwab CW, McGonigal MD, et al. 'Damage control': an approach for improved survival in exsanguinating penetrating abdominal injury. J Trauma 1993;35:375-82; discussion 382-3.

19. Pringle JH. V. Notes on the arrest of hepatic hemorrhage due to trauma. Ann Surg 1908;48:541-9.

20. Lucas CE, Ledgerwood AM. Prospective evaluation of hemostatic techniques for liver injuries. J Trauma 1976;16:442-51.

21. Calne RY, McMaster P, Pentlow BD. The treatment of major liver trauma by primary packing with transfer of the patient for definitive treatment. Br J Surg 1979;66:338-9.

22. Carmona RH, Peck DZ, Lim RC Jr. The role of packing and planned reoperation in severe hepatic trauma. J Trauma 1984 24:779-84.

23. Feliciano DV, Mattox KL, Jordan GL Jr. Intra-abdominal packing for control of hepatic hemorrhage: a reappraisal. J Trauma 1981;21:285-90.

24. Svoboda JA, Peter ET, Dang CV, et al. Severe liver trauma in the face of coagulopathy. A case for temporary packing and early reexploration. Am J Surg 1982;144:717-21.

25. Feliciano DV, Pachter HL. Hepatic trauma revisited. Curr Probl Surg 1989;26:453-524.

26. Sharp KW, Locicero RJ. Abdominal packing for surgically uncontrollable hemorrhage. Ann Surg 1992;215:467-74; discussion 474-5

27. Talbert S, Trooskin SZ, Scalea T, et al. Packing and re-exploration for patients with nonhepatic injuries. J Trauma 1992;33:121-4; discussion 124-5

28. Diaz JJ Jr, Cullinane DC, Dutton WD, et al. The management of the open abdomen in trauma and emergency general surgery: part 1-damage control. J Trauma 2010;68:1425-38.

29. Godat L, Kobayashi L, Costantini T, et al. Abdominal damage contro surgery and reconstruction: world society of emergency surgery position paper. World J Emerg Surg 2013;8:53.

30. Kirkpatrick AW, Roberts DJ, De Waele J, et al. Intra-abdominal hypertension and the abdominal compartment syndrome: updated consensus definitions and clinical practice guidelines from the World Society of the Abdominal Compartment Syndrome. Intensive Care Med 2013;39:1190-206.

31. Moore EE, Burch JM, Franciose RJ, et al. Staged physiologic restoration and damage control surgery. World J Surg 1998;22:1184-90; discussion 1190-1.

32. Johnson JW, Gracias VH, Schwab CW, et al. Evolution in damage control for exsanguinating penetrating abdominal injury. J Trauma 2001:51:261-9; discussion 269-71.

33. Chovanes J, Cannon JW, Nunez TC. The evolution of damage control surgery. Surg Clin North Am 2012;92:859-75, vii-viii.

34. Cirocchi R, Abraha I, Montedori A, et al. Damage control surgery for abdominal trauma. Cochrane Database Syst Rev 2010;(1): CD007438.

35. Bach A, Bendix J, Hougaard K, et al. Retroperitoneal packing as part of damage control surgery in a Danish trauma centre-fast, effective, and cost-effective. Scand J Trauma Resusc Emerg Med 2008;16:4.

36. Cotton BA, Gunter OL, Isbell J Jr, et al. Damage control hematology the impact of a trauma exsanguination protocol on survival and blood product utilization. J Trauma 2008;64:1177-82; discussion 1182-3.

37. Hirshberg A, Wall MJ Jr, Mattox KL. Planned reoperation for trauma: a two year experience with 124 consecutive patients. J Trauma 1994:37:365-9.

38. Saifi J, Fortune JB, Graca L, et al. Benefits of intra-abdominal pack placement for the management of nonmechanical hemorrhage. Arch Surg 1990;125:119-22.

39. Barkun JS, Aronson JK, Feldman LS, Balliol Collaboration, et al. Evaluation and stages of surgical innovations. Lancet 2009;374:1089-96.

40. Cotton BA, Reddy N, Hatch QM, et al. Damage control resuscitation is associated with a reduction in resuscitation volumes and improvement in survival in 390 damage control laparotomy patients. Ann Surg 2011;254:598-605

41. Duchesne JC, Kimonis K, Marr AB, et al. Damage control resuscitation in combination with damage control laparotomy: a survival advantage. J Trauma 2010;69:46-52.

42. Spoerke N, Michalek J, Schreiber M, et al.; Trauma Outcomes Group. Crystalloid resuscitation improves survival in trauma patients receiving low ratios of fresh frozen plasma to packed red blood cells. J Trauma 2011;71:S380-3.

43. Batacchi S, Matano S, Nella A, et al. Vacuum-assisted closure device enhances recovery of critically ill patients following emergency surgical procedures. Crit Care 2009;13:R194.

44. Bee TK, Croce MA, Magnotti LJ, et al. Temporary abdominal closure techniques: a prospective randomized trial comparing polyglactin 
910 mesh and vacuum-assisted closure. J Trauma 2008;65:337-42; discussion 342-4.

45. Boele van Hensbroek P, Wind J, Dijkgraaf MG, et al. Temporary closure of the open abdomen: a systematic review on delayed primary fascial closure in patients with an open abdomen. World $J$ Surg 2009;33:199-207.

46. Miller PR, Meredith JW, Johnson JC, et al. Prospective evaluation of vacuum-assisted fascial closure after open abdomen: planned ventral hernia rate is substantially reduced. Ann Surg 2004;239:608-14; discussion 614-6.

47. Miller PR, Thompson JT, Faler BJ, et al. Late fascial closure in lieu of ventral hernia: the next step in open abdomen management. $J$ Trauma 2002;53:843-9.

48. Pliakos I, Papavramidis TS, Mihalopoulos N, et al. Vacuum-assisted closure in severe abdominal sepsis with or without retention sutured sequential fascial closure: a clinical trial. Surgery 2010; 148:947-53.

49. Perez D, Wildi S, Demartines N, et al. Prospective evaluation of vacuum-assisted closure in abdominal compartment syndrome and severe abdominal sepsis. J Am Coll Surg 2007;205: 586-92.

50. Roberts DJ, Jenne CN, Ball CG, et al. Efficacy and safety of active negative pressure peritoneal therapy for reducing the systemic inflammatory response after damage control laparotomy (the Intra-peritoneal Vacuum Trial): study protocol for a randomized controlled trial. Trials 2013;14:141.

51. Hatch QM, Osterhout LM, Ashraf A, et al. Current use of damage-control laparotomy, closure rates, and predictors of early fascial closure at the first take-back. J Trauma 2011; 70:1429-36.

52. Hatch QM, Osterhout LM, Podbielski J, et al. Impact of closure at the first take back: complication burden and potential overutilization of damage control laparotomy. J Trauma 2011;71:1503-11.

53. Martin MJ, Hatch Q, Cotton B, et al. The use of temporary abdominal closure in low-risk trauma patients: Helpful or harmful? J Trauma Acute Care Surg 2012;72:601-6.

54. Cheatham ML, Safcsak K, Llerena LE, et al. Long-term physical, mental, and functional consequences of abdominal decompression. $J$ Trauma 2004;56:237-41; discussion 241-2.

55. Montalvo JA, Acosta JA, Rodriguez P, et al. Surgical complications and causes of death in trauma patients that require temporary abdominal closure. Am Surg 2005;71:219-24.

56. Regner JL, Kobayashi L, Coimbra R. Surgical strategies for management of the open abdomen. World J Surg 2012;36: 497-510.

57. Asensio JA, McDuffie L, Petrone $P$, et al. Reliable variables in the exsanguinated patient which indicate damage control and predict outcome. Am J Surg 2001;182:743-51.

58. Asensio JA, Petrone P, O'Shanahan G, et al. Managing exsanguination: what we know about damage control/bailout is not enough. Proc (Bayl Univ Med Cent) 2003;16:294-6.

59. Asensio JA, Petrone P, Roldan G, et al. Has evolution in awareness of guidelines for institution of damage control improved outcome in the management of the posttraumatic open abdomen? Arch Surg 2004;139:209-14; discussion 215.
60. Tremblay LN, Feliciano DV, Rozycki GS. Assessment of initial base deficit as a predictor of outcome: mechanism of injury does make a difference. Am Surg 2002;68:689-93; discussion 693-4.

61. Ouellet JF, Roberts DJ, Tiruta C, et al. Admission base deficit and lactate levels in Canadian patients with blunt trauma: are they useful markers of mortality?. J Trauma Acute Care Surg 2012;72:1532-5.

62. Roberts DJ, Zygun DA, Grendar J, et al. Negative-pressure wound therapy for critically ill adults with open abdominal wounds: a systematic review. J Trauma Acute Care Surg 2012;73:629-39.

63. The RAND/UCLA appropriateness method user's manual. http:// www.rand.org/pubs/monograph_reports/MR1269.html (accessed 1 Jan 2014)

64. Arksey H, O'Malley L. Scoping studies: towards a methodological framework. Int J Soc Res Methodol 2005;8:19-32.

65. Levac D, Colquhoun H, O'Brien KK. Scoping studies: advancing the methodology. Implement Sci 2010;5:69.

66. Daudt HM, van Mossel C, Scott SJ. Enhancing the scoping study methodology: a large, inter-professional team's experience with Arksey and O'Malley's framework. BMC Med Res Methodol 2013;13:48.

67. Elo $\mathrm{S}$, Kyngas $\mathrm{H}$. The qualitative content analysis process. J AdV Nurs 2008;62:107-15.

68. Hsieh HF, Shannon SE. Three approaches to qualitative content analysis. Qual Health Res 2005;15:1277-88.

69. Straus AL, Corbin J. Basics of qualitative research: techniques and procedures for developing grounded theory. 3rd edn. London: Sage, 2007.

70. Willig C. Part 2: doing research—grounded theory methodology. In: Willig C, ed. Introducing qualitative research in psychology. 3rd edn. London, UK: Open University Press, 2013:69-82.

71. Ivatury RR, Malhotra AK. Damage control. In: Wilson WC, Grande CM, Hoyt DB, eds. Trauma: emergency resuscitation, perioperative anesthesia, surgical management. New York, NY: Informa Healthcare USA Inc, 2007:405-16.

72. Etext on Health Technology Assessment (HTA) Information Resources. Using a search protocol to identify sources of information: the COSI model. http://www.nlm.nih.gov/archive/ 20060905/nichsr/ehta/chapter3.html\#COSI (accessed 10 Dec 2013).

73. Landis JR, Koch GG. The measurement of observer agreement for categorical data. Biometrics 1977;33:159-74.

74. Altman DG, ed. Practical Statistics for Medical Research. London: Chapman \& Hall, 1991.

75. Oleckno WA. An overview of epidemiologic study designs. In: Oleckno WA, ed. Epidemiology: concepts and methods long grove. Illinois: Waveland Press Inc, 2008:55-84.

76. Dekkers OM, Egger M, Altman DG, et al. Distinguishing case series from cohort studies. Ann Intern Med 2012;156:37-40.

77. Guide to knowledge translation at CIHR: integrated and end-of-grant approaches. http://www.cihr-irsc.gc.ca/e/documents/kt_Im_ktplan-en. pdf (accessed 5 Mar 2013).

78. Obertop H. How surgeons make decisions: authority and evidence. Ann Surg 2005;242:753-6.

79. Young JM, Hollands MJ, Ward J, et al. Role for opinion leaders in promoting evidence-based surgery. Arch Surg 2003; 138:785-91. 